\title{
Fatty acid alkyl ester and wax compositions of olive oils as varietal authentication indicators
}

\author{
Oguz Uncu' ${ }^{1}$ (D) Banu Ozen ${ }^{1}$ (D)
}

Received: 12 June 2021 / Accepted: 29 September 2021 / Published online: 8 October 2021

(c) The Author(s), under exclusive licence to Springer Science+Business Media, LLC, part of Springer Nature 2021

\begin{abstract}
Minor components of olive oils can be good markers for their authenticity, which is a significant quality issue for this product. It was aimed to determine individual and total fatty acid alkyl esters and waxes as minor constituents of olive oil and to investigate their novel varietal authentication capability separately and in combination for three main olive cultivars grown in three distinct locations of Aegean Region of Turkey. In addition, basic quality and purity parameters as free fatty acid, $\mathrm{K}$ values and fatty acid profiles were also determined for the characterization of the samples. Olive oil samples from different cultivars had different fatty acid profiles and two of these varieties had similar quality parameters. Statistical analyses were conducted with orthogonal partial least squares discriminant analysis (OPLS-DA) to differentiate varieties with respect to their individual and combined parameters of fatty acid alkyl esters and waxes. For calibration sets, use of individual fatty acid alkyl esters profile resulted in $80 \%$ correct classification rate while waxes alone was $67 \%$ successful in classifying the olive oils according to variety. It was found that alkyl esters in combination with waxes were more effective in discrimination of olive oils with respect to cultivar compared to their individual forms and the correct classification rate for the generated model is $92 \%$ for calibration set. Since fatty acid alkyl esters along with waxes have effect on cultivar differentiation, they could have a potential as authentication tools for olive oil besides their known quality characteristics.
\end{abstract}

Keywords Olive oil $\cdot$ Variety $\cdot$ Authentication $\cdot$ Fatty acid alkyl esters $\cdot$ Waxes

\section{Introduction}

Minor compounds could be effective indicators of the authenticity and quality of the olive oils since they are hard to mimic in complex matrices [1]. Among them fatty acid alkyl esters (FAAEs) and waxes are prominent compounds since they are considered as robust markers of olive oil quality. Fatty acid alkyl esters as ethyl (FAEEs) and methyl esters (FAMEs) are a family of natural neutral lipids present in olive oils and formed by the esterification of free fatty acids (FFAs) with low molecular weight alcohols, ethanol and methanol, respectively [2]. They can easily form in an acid medium and the reaction is catalyzed by certain enzymes [2]. According to an early European Union regulation for FAAE content, the limit was set at $75 \mathrm{mg} / \mathrm{kg}$, but higher concentrations were allowed if they did not exceed $150 \mathrm{mg} / \mathrm{kg}$

Banu Ozen

banuozen@iyte.edu.tr

1 Department of Food Engineering, Izmir Institute of Technology, Urla-Izmir, Turkey and FAEE/FAME ratio was 1.5 at the maximum [3-5]. The knowledge of ethanol production as a metabolic by-product after alcoholic fermentation [6] led to a conclusion that the presence of high concentrations of both FAEE and ethanol in olive oil could mean the use of sub-standard quality raw materials such as fermented olive fruits for oil extraction [4]. Therefore, new limits were officially published by the olive oil authorities due to the fact that FAEEs presence depended on the level of its substrate, ethanol, which is produced chemically whereas FAMEs are associated with methanol content produced physiologically $[1,7]$. Moreover, only C16 FAEE and C18 FAEE were taken into consideration in the regulation to decide if a certain olive oil could be classified as extra virgin [4]. This decision was accompanied by a reduction of the maximum allowed limit to $40 \mathrm{mg} / \mathrm{kg}$ (2013-14 crop year) [4]. Limits regarding the fatty acid ethyl ester (FAEE) presence in extra virgin olive oil were further lowered to $\leq 35 \mathrm{mg} / \mathrm{kg}$ after 2016 harvest year [1].

In a previous study, a relationship between the FAAEs concentration of olive oils and their sensory classification was also evaluated. The results showed that there is a strong 
connection between the presence of high amounts of FAAEs and fermentative organoleptic defects [4]. FAAE has also been used for adulteration detection of olive oil with mild deodorized olive oil $[2,8]$.

In addition to the fermentative effect of unhealthy olive fruits, it was revealed that ethanol formation is also triggered by the metabolism of the olive fruit itself which is highly related with cultivar (genotype) of the fruit [9]. Accumulation is continued during fruit maturation on the olive tree [9]. All of these make usage of FAEEs more complex since this parameter is affected by both quality and variety [10]. A different study also confirmed that ethanol is naturally found in the olive fruits and it passes to the oil during extraction. As a result, it was determined that concentration of the ethanol in the oil was a function of the cultivar, ripening stage and climate as well as growing conditions of the olives [7]. Therefore, it was suggested that legislations on FAEEs should consider the basal levels of ethanol in the oils as it is quite high in many olive cultivars [7]. Hence, it is not appropriate to use unique FAEE values for all olive varieties [10]. In a recent study, it was determined that not only ethanol but also methanol content and acetaldehyde as well as the ratio between them are characteristic to each olive variety [10]. Hence, it could be concluded that individual FAAEs and their specific ratio which have not been studied for the varietal determination before could possess a potential as an authentication tool for olive oils.

In a literature study, Fourier transform infrared (FTIR) spectroscopy was used to separate virgin and non-virgin olive oils according to the FAEEs content [11]. In another recent work, alkyl esters content of Sicilian extra virgin olive oils having Protected Designation of Origin (PDO) was investigated from quality perspective only [12]. However, there is not any authentication study in the literature focusing on alkyl esters alone from varietal point of view.

Other investigated quality parameter in the current study is wax content of olive oil. The straight chain wax esters are also shown to be useful indicators for the quality of olive oil. They are in the waxy surface layer of the olive and are poorly extracted by the oil derived from fruit pressing [2]. Wax content has been also defined as a quality indicator and extra virgin olive oil wax content must not exceed $150 \mathrm{mg} / \mathrm{kg}$ according to the existing regulations $[13,14]$. Wax esters have been generally used for quality determination [2] as well as detection of adulteration made with lower quality olive oil or pomace oil [15]. Individual and total wax esters of Spanish monovarietal olive oils with PDO were determined and it was found that significant differences existed in C40, C44, C46 and total wax esters content [16]. These findings were also supported by a study performed with Italian cultivars and it was proven that wax ester content was influenced by cultivar and harvest year [17] as well as ripening [18].
Results of these studies were also confirmed by a research in which wax esters, diacylglycerols, triacylglycerols, triterpenic acids and aldehydes were shown to be strongly dependent on the olive cultivar [19]. Authenticity is an important quality issue for different types of food products such as honey, wine and various types of oils [20-23] and olive oil is among the most adulterated food products [1]. Therefore, new authenticity methods and studies are always in demand for olive oil industry in order to protect the safety and the quality as well as the economic value of this product.

Although all this aforementioned information makes the individual and combined forms of FAAEs and waxes as good candidates of authentication markers for botanical origin of olive oils, there is no study in literature about their application in varietal differentiation. Until so far, FAEE and FAME as well as wax esters have already been used for evaluating only the quality of olive oils $[2,24]$. In the present study, it was aimed to investigate the potential of FAEEs, FAMEs and wax esters determined with chromatographic methods by evaluating with chemometric techniques individually and in combination to authenticate olive oils with respect to variety.

\section{Materials and methods}

\section{Olive oil samples}

Totally 91 authentic olive oil samples from various parts of Aegean Region of Turkey were collected directly from the trustworthy sources during two consecutive harvest year. These samples were scattered in three main growing location of the Aegean Region as North (N: 29 samples), South (S: 36 samples) and Middle (M: 26 samples). The North and South regions are geographical indication areas while Middle region could be a candidate for the same type of labelling due to unique characteristics of oils. At the same time, these geographical regions are specific to certain varieties of olive fruits. Ayvalik/Edremit is the cultivar grown in northern part while Memecik type belongs to the southern part and Erkence is the dominant variety of mid part. The samples were kept in dark at refrigeration temperature $\left(4^{\circ} \mathrm{C}\right)$ with minimum headspace filled with inert gas prior to analysis. They were analyzed right after receiving.

\section{Chemical reagents}

Reagents are all analytical grade and obtained from SigmaAldrich (Munich, Germany) and/or Merck (Darmstadt, Germany) unless otherwise stated. 


\section{Quality parameters}

Basic quality parameters, free fatty acid (FFA) value, specific extinction coefficients (K232 and K270) and fatty acid profile of the olive oil samples were quantified according to European Official Methods of Analysis [25].

Briefly, FFA values determination was based on titration in which a desired color change obtained by using phenolphthalein as indicator. First, olive oil sample was dissolved in diethyl ether-ethanol solution (1:1) with addition of few drops of indicator and then titrated with standardized $0.1 \mathrm{~mol} / \mathrm{L}$ solution of potassium hydroxide. Analyses were repeated two times and expressed in terms of average \% oleic acid.

$\mathrm{K}$ values of the samples were determined spectrophotometrically. Absorbance values at 232 and $270 \mathrm{~nm}$ were recorded with a spectrophotometer (Shimadzu UV-2450 Spectrophotometer, Japan) by diluting the oil samples with cyclohexane and using pure cyclohexane as the blank. Measurements were obtained twice and then averaged.

Gas chromatography with flame ionization detector (GC-FID) (Agilent 6890, Agilent Technologies, USA) was used to determine fatty acid profile of the methyl esterified olive oil samples. The system had an auto-sampler (Agilent 7863) with a split/splitless inlet. A capillary HP-88 column $(100 \mathrm{~m} \times 0.25 \mathrm{~mm}$ ID $\times 0.2 \mathrm{~mm})$ (Agilent) was used to fractionate the compounds. Operation conditions were determined as follows; $1 \mu \mathrm{L}$ eluent was injected with a split ratio $1 / 50$, helium was used as a carrier gas in constant flow ( $2 \mathrm{~mL} / \mathrm{min}$ flow), the temperature of injector and detector were set to $250{ }^{\circ} \mathrm{C}$ and $280^{\circ} \mathrm{C}$, respectively. The temperature program of oven was constant at $120^{\circ} \mathrm{C}$ for $10 \mathrm{~min}$ and then increased to $220{ }^{\circ} \mathrm{C}$ with a rate of $3{ }^{\circ} \mathrm{C}$ per min. and maintained at the same temperature for $5 \mathrm{~min}$. The chromatogram peaks of each sample were used to identify and quantify major individual fatty acids by comparing the retention times of FAME mix standards. Triplicate measurements were done and then averaged.

\section{Quantification of fatty acid alkyl ester and wax contents}

FAMEs and FAEEs as well as wax contents of olive oil samples were determined according to the procedures of International Olive Council (IOC) [26]. Fifteen $g$ of silica gel wetted with n-hexane was inserted into the glass column and then percolated with n-hexane to remove any impurities. After that, approximately $0.5 \mathrm{~g}$ of the olive oil sample was weighted with the addition of internal standards as dodecyl arachidate and methyl heptadecanoate solution for waxes and alkyl esters, respectively. Sudan 1 was used as an indicator dye. Then, the mixture was transferred into the glass column via n-hexane. Sample was continuously percolated with n-hexane/ethyl ether mixture (99:1) until indicator dye reaches to the bottom. The collected solution was evaporated in a rotary evaporator (Heidolph Laborota-4000, Germany) at $20^{\circ} \mathrm{C}$. The residual was diluted with $2 \mathrm{~mL}$-heptane then filtered into a vial and finally injected into GC.

The analysis was conducted with Agilent 7890A GCFID. HP-5 (30 m $\times 0.32 \mathrm{~mm}$ ID, $0.25 \mu \mathrm{m}$ film, Agilent) column was used with the following conditions: $70{ }^{\circ} \mathrm{C}$ was selected as on column inlet temperature and injection volume was set to $1 \mu \mathrm{L}$. The hydrogen was used as carrier gas. The oven temperature was programmed as $80^{\circ} \mathrm{C}$ for $1 \mathrm{~min}$, $20{ }^{\circ} \mathrm{C} / \mathrm{min}$ to $140{ }^{\circ} \mathrm{C}$ without stop, $5{ }^{\circ} \mathrm{C} / \mathrm{min}$ to $335^{\circ} \mathrm{C}$ for $20 \mathrm{~min}$. Detector temperature was selected as $350^{\circ} \mathrm{C}$. The obtained peaks were further identified with GC-MS (Agilent 6890/5973 N Network GC/MSD System, USA) at the same conditions. The results were expressed in terms of $\mathrm{mg} / \mathrm{kg}$.

\section{Statistical analysis}

SIMCA 14.1 (Umetrics, Malmö, Sweden) software was used for the statistical evaluations. Orthogonal partial least squares discriminant analysis (OPLS-DA) was the preferred multivariate statistical analysis tool throughout the study to visualize discrimination among the groups of interest. OPLS-DA is a supervised data classification technique, in which the relationship between two data matrices as measured $X$ giving information about the wet chemical data and as dummy Y relying on user-defined class information, was investigated [27]. For chemometric analysis, fatty acid profile matrix included 91 rows (samples) and 11 columns (individual fatty acids). Fatty acid alkyl ester and wax matrices, separately and in together, possessed the same number of samples (91) with 16 columns for combined data (individual and total alkyl esters and waxes), 4 columns for waxes and the rest 12 columns for alkyl esters. The basic parameters, FFA and $\mathrm{K}$ values, were also evaluated together.

Prior to construction of discrimination models, all the raw chemical data matrices were pre-processed with unit variance scaling and mean-centering without any further treatment. Pre-treated data of FFA and K values as well as fatty acid profile were modelled with only calibration set to see if there is any differentiation pattern with respect to the main cultivar. Whereas, in the alkyl ester and wax evaluation, more detailed models were constructed by using a calibration and an external validation dataset, comprising $2 / 3$ of the total and the rest, respectively. Calibration dataset contains 60 samples in three classes as 17 Middle (class M), 19 North (class N), and 24 South (class S) samples, whereas 31 samples as $9 \mathrm{M}, 10 \mathrm{~N}$, and $12 \mathrm{~S}$ were used as the validation data set.

Classification performances of these models were inspected with several parameters such as numbers of latent variables (LVs) and regression coefficients for both 
calibration $\left(\mathrm{R}_{\text {cal }}^{2}\right)$ and validation $\left(\mathrm{R}_{\mathrm{cv}}^{2}\right)$ models along with correct classification rate for the same models. External validation $\left(\mathrm{R}_{\text {val }}^{2}\right)$ was also performed for the specific OPLS-DA model using alkyl ester and wax data matrix by applying sevenfold LVs embedded function of SIMCA software to avoid any over and/or under fitting. Another parameter was variable importance for the projection (VIP) values which were obtained with SIMCA software and used to determine the most effective variables in differentiation. If the VIP values of variables are greater or close to 1, they are considered as significant variables for the OPLS-DA model [27].

\section{Results and discussion}

\section{Chemical characterization}

Quality parameters (FFA and K values) of the olive oil samples are provided in Table 1. According to this table, $\mathrm{M}$ region samples were in lower quality in terms of measured parameters when compared with the other two regions ( $\mathrm{N}$ and $\mathrm{S}$ ). Average FFA value of $\mathrm{M}$ region samples was $3.28 \%$ $( \pm 2.28)$ while $S$ and $N$ samples had average FFA values of $0.76 \%( \pm 0.51)$ and $0.60 \%( \pm 0.14)$, respectively. K232 $(2.60 \pm 0.28)$ and $\mathrm{K} 270(0.29 \pm 0.17)$ values of $\mathrm{M}$ region oils were also higher compared to oils from other N (K232: $2.19 \pm 0.24, \mathrm{~K} 270: 0.24 \pm 0.07)$ and $\mathrm{S}(\mathrm{K} 232: 2.26 \pm 0.21$, K270: $0.21 \pm 0.08$ ) region oils. These parameters are strict quality parameters for grading olive oils according to European Legislations. In this part, it was not intended to make a classification but rather it was aimed to investigate the differences in quality characteristics of the oil samples with respect to their variety so that better conclusions could be drawn from FAAE and wax data. Therefore, OPLS-DA models were constructed with the quality data set (FFA and K values) as shown in Fig. 1. Differentiation model was built with 2 predictive components and these LVs explained $31 \%$ of the total variance.

As far as the varietal origins are concerned it could be seen that $\mathrm{N}$ and $\mathrm{S}$ samples were not generally separated from each other while most of $\mathrm{M}$ region samples were grouped distantly from the others with respect to LV1 in the score plot (Fig. 1). M region samples were apart from the other two regions due to their lower quality characteristics. In detail, three samples were misclassified for $\mathrm{M}$ region whereas other regions ( $\mathrm{N}$ and $\mathrm{S}$ ) were mostly placed together (Fig. 1). This could be explained by the fact that quality characteristics of the samples from $\mathrm{N}$ and $\mathrm{S}$ regions were similar to each other having smaller ranges as it can be seen from Table 1 .

Individual fatty acid contents of the samples from different areas were close to each other. However, differences in oleic and linoleic acid contents were observed between
Table 1 Averages of chemical parameters of olive oils obtained from different varietal origin

\begin{tabular}{|c|c|c|c|}
\hline $\begin{array}{l}\text { Chemical param- } \\
\text { eters }\end{array}$ & $\begin{array}{l}\text { North region } \\
\text { (N) (Ayvalik) }\end{array}$ & $\begin{array}{l}\text { South } \\
\text { region (S) } \\
\text { (Memecik) }\end{array}$ & $\begin{array}{l}\text { Middle region } \\
\text { (M) (Erkence) }\end{array}$ \\
\hline FFA $(\%)^{1}$ & $0.60 \pm 0.14$ & $0.76 \pm 0.51$ & $3.28 \pm 2.28$ \\
\hline \multicolumn{4}{|l|}{$k$ values } \\
\hline $\mathrm{K} 232^{2}$ & $2.19 \pm 0.24$ & $2.26 \pm 0.21$ & $2.60 \pm 0.28$ \\
\hline $\mathrm{K} 270^{3}$ & $0.24 \pm 0.07$ & $0.21 \pm 0.08$ & $0.29 \pm 0.17$ \\
\hline \multicolumn{4}{|l|}{$\begin{array}{l}\text { Fatty acid profile } \\
(\%)\end{array}$} \\
\hline $\mathrm{C} 16: 0^{4}$ & $14.68 \pm 1.21$ & $13.36 \pm 1.01$ & $13.36 \pm 1.12$ \\
\hline $\mathrm{C} 16: 1^{5}$ & $0.84 \pm 0.11$ & $0.89 \pm 0.21$ & $0.72 \pm 0.25$ \\
\hline $\mathrm{C} 17: 0^{6}$ & $0.16 \pm 0.08$ & $0.08 \pm 0.08$ & $0.16 \pm 0.07$ \\
\hline $\mathrm{C} 17: 1^{7}$ & $0.24 \pm 0.04$ & $0.13 \pm 0.10$ & $0.22 \pm 0.03$ \\
\hline $\mathrm{C} 18: 0^{8}$ & $2.81 \pm 0.28$ & $2.79 \pm 0.36$ & $2.81 \pm 0.22$ \\
\hline $\mathrm{C} 18: 1 \mathrm{n} 9 \mathrm{c}^{9}$ & $68.75 \pm 1.15$ & $71.21 \pm 2.19$ & $66.53 \pm 1.53$ \\
\hline $\mathrm{C} 18: 2 \mathrm{n} 6 \mathrm{c}^{10}$ & $11.09 \pm 1.10$ & $9.94 \pm 1.34$ & $14.60 \pm 2.29$ \\
\hline $\mathrm{C} 20: 0^{11}$ & $0.43 \pm 0.06$ & $0.41 \pm 0.06$ & $0.43 \pm 0.04$ \\
\hline $\mathrm{C} 18: 3 \mathrm{n} 3^{12}$ & $0.65 \pm 0.06$ & $0.81 \pm 0.09$ & $0.76 \pm 0.11$ \\
\hline $\mathrm{C} 20: 1^{13}$ & $0.28 \pm 0.06$ & $0.30 \pm 0.06$ & $0.31 \pm 0.03$ \\
\hline $\mathrm{C} 22: 0^{14}$ & $0.07 \pm 0.10$ & $0.08 \pm 0.11$ & $0.11 \pm 0.03$ \\
\hline \multicolumn{4}{|l|}{$\begin{array}{l}\text { Fatty acid alkyl } \\
\text { esters and } \\
\text { waxes }(\mathrm{mg} / \mathrm{kg})\end{array}$} \\
\hline $\mathrm{C} 16: 0 \mathrm{M}^{15}$ & $3.87 \pm 1.40$ & $4.15 \pm 1.97$ & $17.49 \pm 16.08$ \\
\hline $\mathrm{C} 16: 0 \mathrm{E}^{16}$ & $2.17 \pm 1.61$ & $3.69 \pm 2.62$ & $20.13 \pm 11.53$ \\
\hline $\mathrm{C} 18: 2 \mathrm{M}^{17}$ & $1.97 \pm 0.77$ & $2.17 \pm 1.08$ & $19.89 \pm 36.74$ \\
\hline $\mathrm{C} 18: 1 \mathrm{M}^{18}$ & $11.18 \pm 4.93$ & $13.66 \pm 7.29$ & $69.11 \pm 49.38$ \\
\hline $\mathrm{C} 18: 0 \mathrm{M}^{19}$ & $0.88 \pm 0.27$ & $0.90 \pm 0.22$ & $4.61 \pm 8.52$ \\
\hline $\mathrm{C} 18: 2 \mathrm{E}^{20}$ & $1.31 \pm 0.83$ & $2.29 \pm 2.00$ & $18.53 \pm 11.42$ \\
\hline $\mathrm{C} 18: 1 \mathrm{E}^{21}$ & $8.36 \pm 6.36$ & $15.74 \pm 12.06$ & $79.72 \pm 48.04$ \\
\hline $\mathrm{C} 18: 0 \mathrm{E}^{22}$ & $0.38 \pm 0.46$ & $0.55 \pm 0.60$ & $3.41 \pm 2.06$ \\
\hline $\mathrm{C} 42^{23}$ & $5.98 \pm 2.81$ & $4.79 \pm 4.47$ & $14.28 \pm 6.11$ \\
\hline $\mathrm{C} 44^{24}$ & $10.26 \pm 4.69$ & $7.46 \pm 5.04$ & $20.92 \pm 11.18$ \\
\hline $\mathrm{C} 48^{25}$ & $5.51 \pm 2.45$ & $5.31 \pm 4.42$ & $11.38 \pm 6.38$ \\
\hline FAEEs $^{26}$ & $12.22 \pm 9.02$ & $22.27 \pm 16.76$ & $121.78 \pm 71.35$ \\
\hline FAMEs $^{27}$ & $17.90 \pm 7.08$ & $20.88 \pm 10.24$ & $111.10 \pm 100.67$ \\
\hline FAAEs $^{28}$ & $30.12 \pm 15.14$ & $43.14 \pm 25.74$ & $232.88 \pm 146.58$ \\
\hline FAEEs/FAMEs ${ }^{29}$ & $0.65 \pm 0.33$ & $0.98 \pm 0.47$ & $1.24 \pm 0.57$ \\
\hline Waxes $^{30}$ & $21.75 \pm 6.53$ & $17.55 \pm 12.43$ & $45.69 \pm 17.78$ \\
\hline
\end{tabular}

${ }^{1}$ Free fatty acid, ${ }^{2,3}$ specific extinction coefficient at $232 \mathrm{~nm}$ and $270 \mathrm{~nm}$, respectively, ${ }^{4}$ palmitic acid, ${ }^{5}$ palmitoleic acid, ${ }^{6}$ heptadecanoic acid, ${ }^{7}$ cis-10-heptadecanoic acid, ${ }^{8}$ stearic acid, ${ }^{9}$ oleic acid, ${ }^{10}$ linoleic acid, ${ }^{11}$ arachidic acid, ${ }^{12}$ linolenic acid, ${ }^{13} \mathrm{cis}$-11-eicosenoic acid, ${ }^{14}$ cis-11,14-eicosadienoic acid, ${ }^{15-22}$ methyl and ethyl forms of the mentioned fatty acids, ${ }^{23-25}$ individual waxes according to carbon number, ${ }^{26}$ total fatty acid ethyl esters, ${ }^{27}$ total fatty acid methyl esters, ${ }^{28}$ total fatty acid ethyl and methyl esters as alkyl esters, ${ }^{29}$ ratio between total ethyl and methyl esters, ${ }^{30}$ total individual waxes

varieties in this study (Table 1) which is consistent with a previous report in the literature [28]. Oleic acid contents of the olive oils from $S$ region were higher $(71.21 \pm 2.19 \%)$ than 
Fig. 1 OPLS-DA score plot of different olive oil varieties in terms basic quality parameters (free fatty acid and $\mathrm{K}$ values)

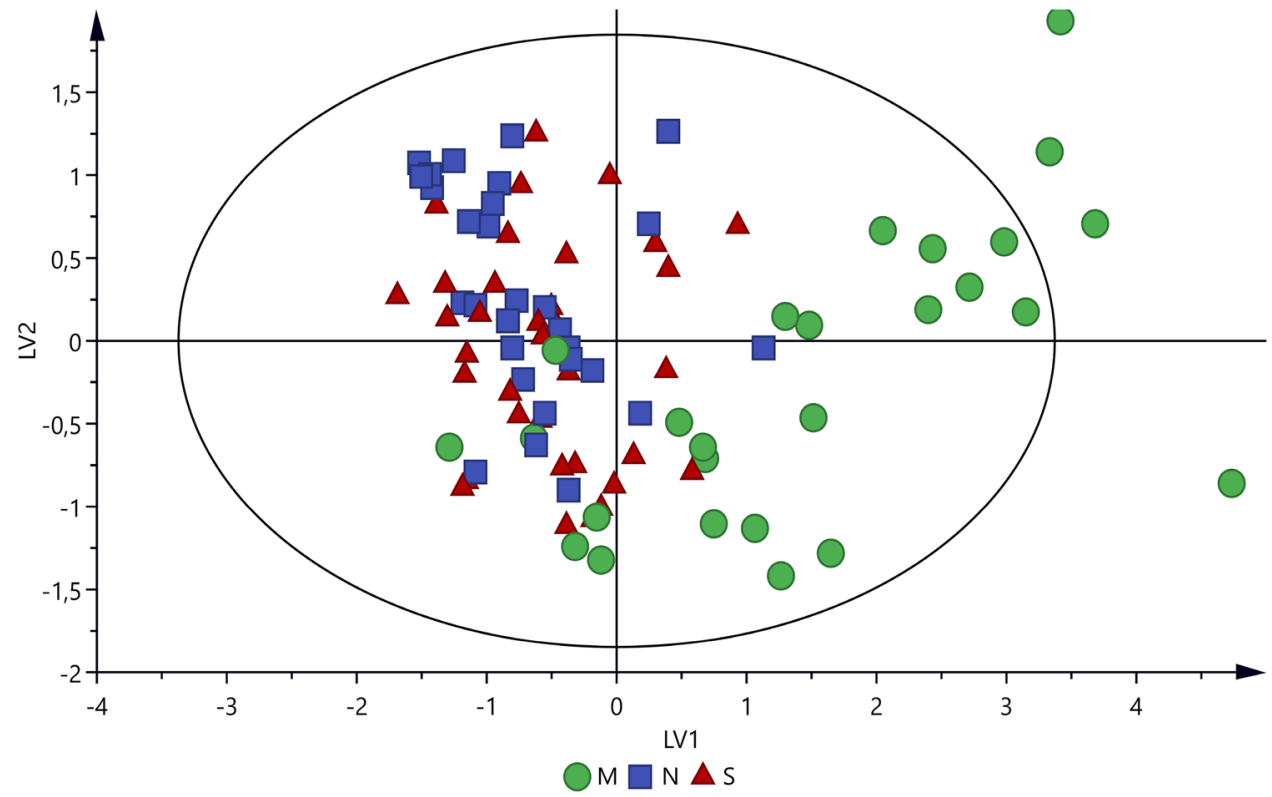

the other two regions (N: $68.75 \pm 1.15 \%, \mathrm{M}: 66.53 \pm 1.53 \%$ ) whereas the opposite is true for linoleic acid contents (S: $9.94 \pm 1.34 \%, \mathrm{~N}: 11.09 \pm 1.10 \%, \mathrm{M}: 14.60 \pm 2.29 \%$ ) (Table 1).

A multivariate data set of 11 fatty acid variables from 91 olive oil samples were used to examine the varietal effect on fatty acid profile. This data set was examined with OPLSDA to observe the differences between cultivars. Model for varietal classification was constructed with 2 predictive and 1 orthogonal component and the first two LVs explained $67 \%$ of the total variance. From the OPLS-DA score plot presented in Fig. 2a, it could be seen that better separation in terms of variety was obtained using fatty acid profile; however, one specific sample from $\mathrm{M}$ region is misclassified as $\mathrm{S}$ and five $\mathrm{M}$ samples are misclassified as $\mathrm{N}$. Therefore, these results reflected the effect of the cultivar in the olive oil classification based on the fatty acid composition, and they also confirm other reports in the literature [29]. Rest of the samples were placed together with the characteristic varieties of the specified regions. Loading plot presented in Fig. $2 b$ shows which fatty acids are responsible for differentiation. For this case, C16:1, C18:1n9c and C18:3n3c are the most effective variables on the separation of $\mathrm{S}$ region. Oils from $\mathrm{M}$ region are separated with respect to $\mathrm{C} 18: 0$, C20:1, C22:0 and C18:2n6c, while C16:0, C17:0, C17:1, and $\mathrm{C} 20: 0$ are the fatty acids responsible for differentiation of $\mathrm{N}$ region. In the literature, three fatty acids as oleic, linoleic and palmitic were indicated as the fatty acids with high differentiation power [29] and these three-fatty acids are also found effective in discrimination of $\mathrm{S}, \mathrm{M}$, and $\mathrm{N}$ regions in the present case. Parameters having variable importance projection (VIP) values greater than 1 are considered as the significant variables in the construction of the statistical models. From the VIP values (Fig. 2c), heptadecenoic and linolenic acids were also found effective in the discrimination of the olive oils in terms of variety besides the aforementioned fatty acids.

\section{Varietal differentiation with alkyl esters and waxes}

Fatty acid alkyl and ethyl ester and wax contents of the sample oils are provided in Table 1. In the present study, it was observed that olive oil samples from $\mathrm{N}(12.22 \mathrm{mg} /$ $\mathrm{kg})$ and $\mathrm{S}(22.27 \mathrm{mg} / \mathrm{kg})$ regions were within the official limit of FAEE for extra virgin grade while the samples from $\mathrm{M}(121.78 \mathrm{mg} / \mathrm{kg})$ region were not (Table 1). On the other hand, samples from all regions are below the limit of wax content. Total wax content averages of oils from N, S and $\mathrm{M}$ regions were $21.75 \mathrm{mg} / \mathrm{kg}, 17.55 \mathrm{mg} / \mathrm{kg}$ and $45.69 \mathrm{mg} /$ $\mathrm{kg}$, respectively. Individual FAAEs and waxes as well as their totals were similar for N (total FAAEs: $30.12 \mathrm{mg} / \mathrm{kg}$ ) and $\mathrm{S}$ (total FAAEs: $43.14 \mathrm{mg} / \mathrm{kg}$ ) region varieties whereas $\mathrm{M}$ region (total FAAEs: $232.88 \mathrm{mg} / \mathrm{kg}$ ) variety had higher contents than these (Table 1). Although most oils from M have lower qualities these oils were intentionally added to the sample set to highlight the differences of FAAE values of high- and low-quality oils.

Alkyl esters and waxes were used individually and in combination to investigate their effects on varietal discrimination. The statistical outputs of all the models are given in Table 2 and Fig. 3. It was seen that wax content, which includes $\mathrm{C} 42$, C44, C48 and total waxes, alone was not that effective in discrimination and only $\mathrm{M}$ region samples were separated from the rest whereas $\mathrm{N}$ samples were misallocated inside the $\mathrm{S}$ samples' half ellipse (Fig. 3a). In detail, OPLS-DA model was built with one predictive and one 
Fig. 2 OPLS-DA score (a), loading (b), and VIP (c) plots of different olive oil varieties in terms of fatty acid profile

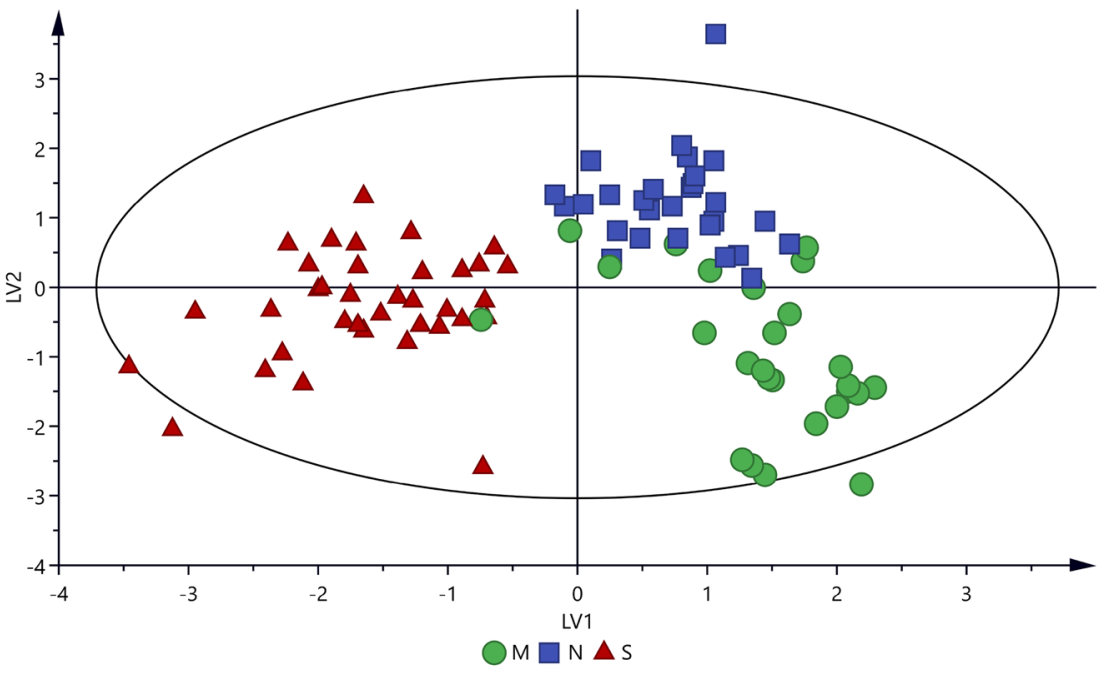

(a)

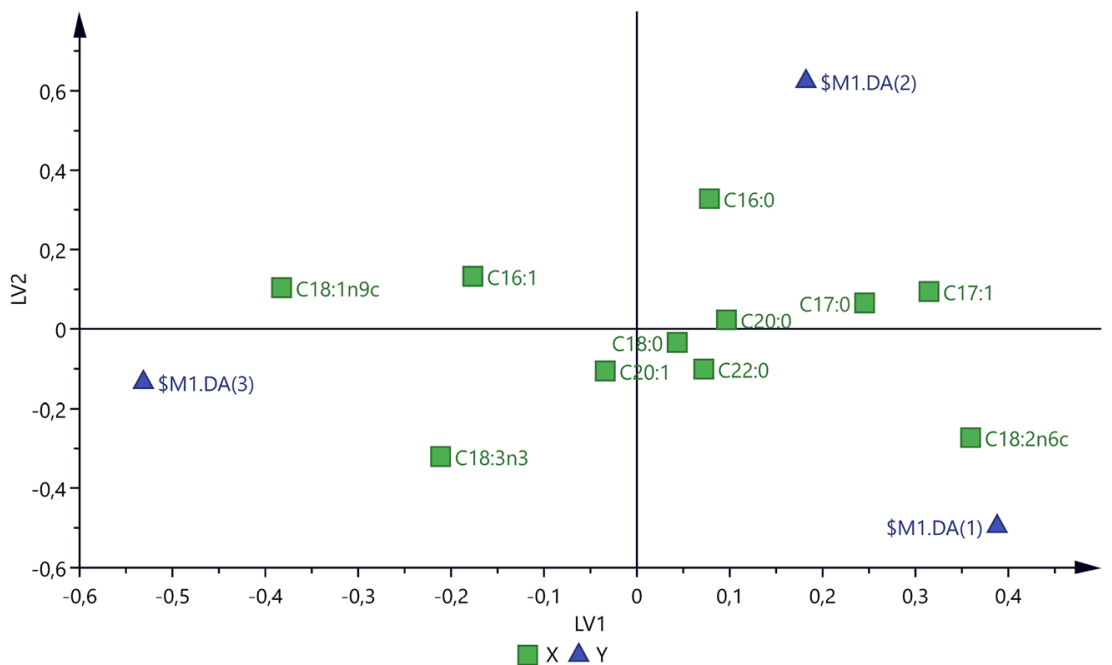

(b)

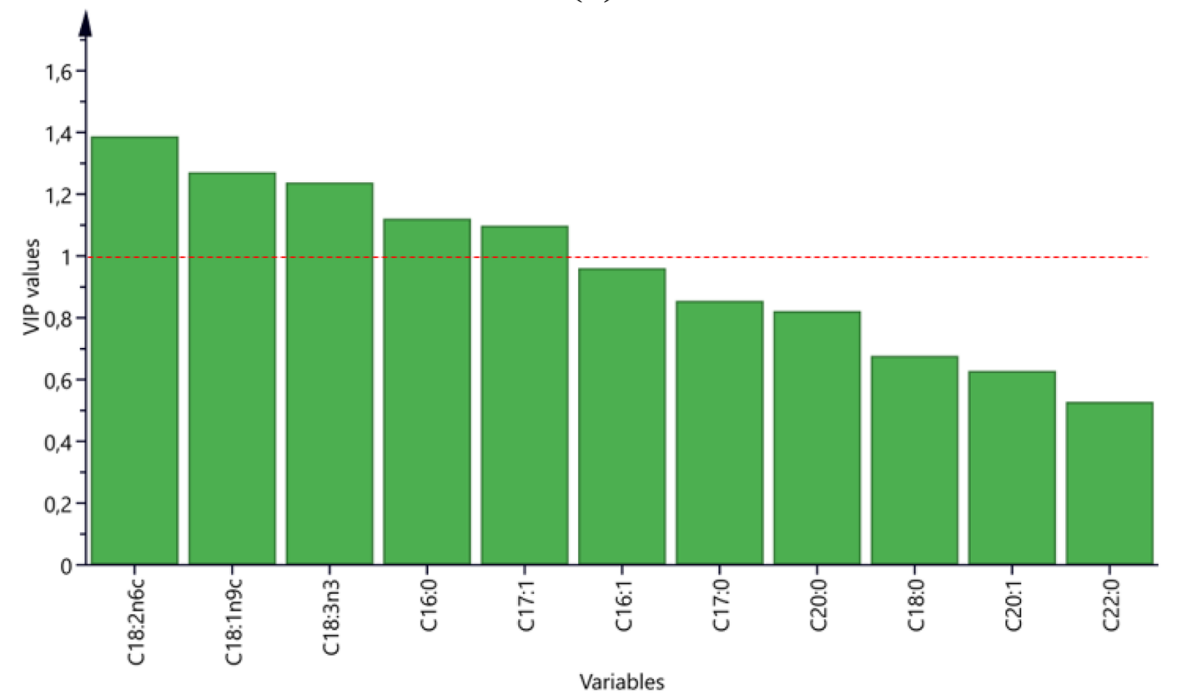

(c) 
Table 2 Statistical parameters of OPLS-DA calibration and validation models of olive oils with respect to variety by using waxes and alkyl esters separately and in combination

\begin{tabular}{|c|c|c|c|c|}
\hline \multirow[t]{3}{*}{ Model } & \multirow{3}{*}{$\begin{array}{l}\text { Number of } \\
\text { samples }\end{array}$} & Waxes & FAAEs & FAAEs and waxes \\
\hline & & $\begin{array}{l}\mathrm{LV}_{\mathrm{s}}: 1+1, \mathrm{R}_{\text {cal. }}^{2}: 0.34 \\
\mathrm{R}_{\text {cv. }}^{2}: 0.32\end{array}$ & $\begin{array}{l}\text { LVs: } 2+2, \mathrm{R}_{\text {cal. }}^{2}: 0.58 \\
\mathrm{R}_{\text {cv. }}^{2}: 0.54\end{array}$ & $\begin{array}{l}\text { LVs: } 2+1, \mathrm{R}_{\text {cal. }}^{2}: 0.67 \\
\mathrm{R}_{\text {cv. }}^{2}: 0.62\end{array}$ \\
\hline & & $\% \mathrm{CC}$ & $\% \mathrm{CC}$ & $\% \mathrm{CC}$ \\
\hline
\end{tabular}

\section{Calibration}

$\begin{array}{lrrrrrrrrrrrrr}\mathrm{M} & 17 & 16 & 0 & 1 & 94 & 15 & 0 & 2 & 88 & 14 & 0 & 3 & 82 \\ \mathrm{~N} & 19 & 1 & 0 & 18 & 0 & 0 & 16 & 3 & 84 & 0 & 18 & 1 & 95 \\ \mathrm{~S} & 24 & 0 & 0 & 24 & 100 & 0 & 7 & 17 & 71 & 0 & 1 & 23 & 96 \\ \text { Total } & 60 & 17 & 0 & 43 & 67 & 15 & 23 & 22 & 80 & 14 & 19 & 27 & 92\end{array}$

Validation

\begin{tabular}{lrrrrrrrrrrrrr}
$\mathrm{M}$ & 9 & 7 & 0 & 2 & 78 & 6 & 2 & 1 & 67 & 7 & 1 & 1 & 78 \\
$\mathrm{~N}$ & 10 & 0 & 0 & 10 & 0 & 0 & 7 & 3 & 70 & 0 & 8 & 2 & 80 \\
$\mathrm{~S}$ & 12 & 3 & 0 & 9 & 75 & 0 & 5 & 7 & 58 & 0 & 4 & 8 & 67 \\
Total & 31 & 10 & 0 & 21 & 52 & 6 & 14 & 11 & 65 & 7 & 13 & 11 & 74 \\
\hline
\end{tabular}

$L V$ latent variable, $F A A E$ fatty acid alkyl ester

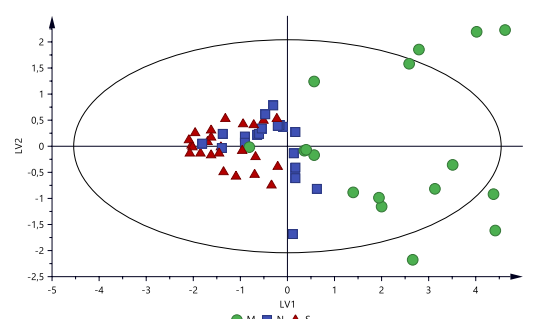

(a)

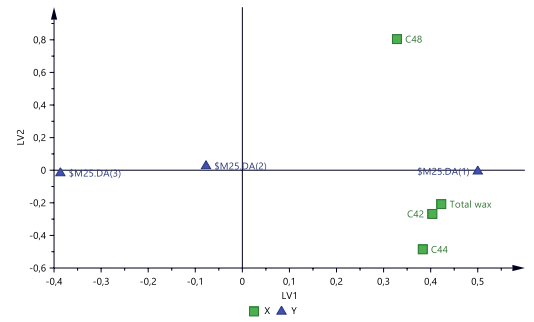

(b)

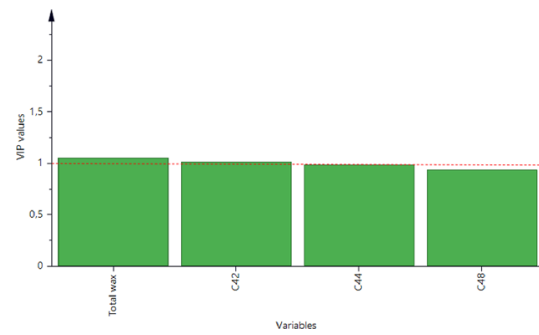

(c)

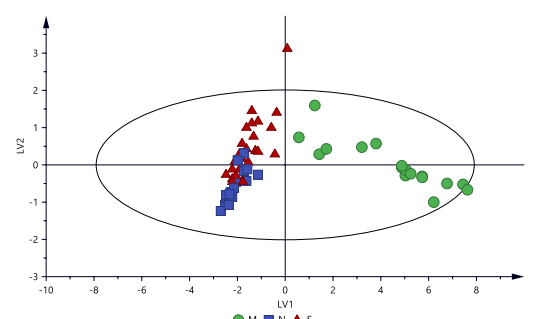

(d)

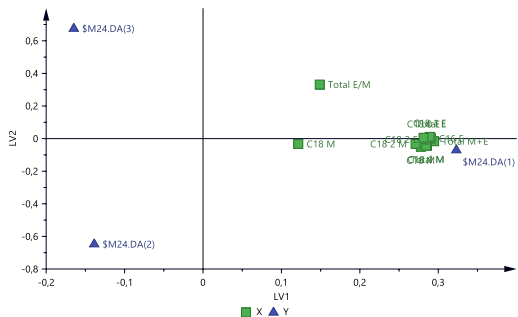

(e)

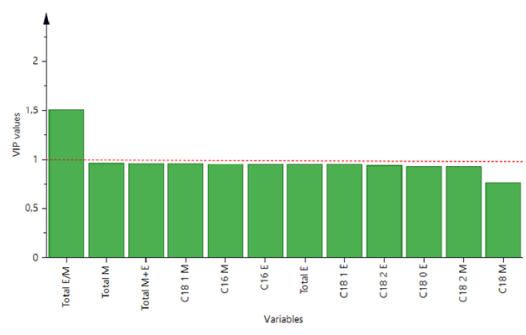

(f)

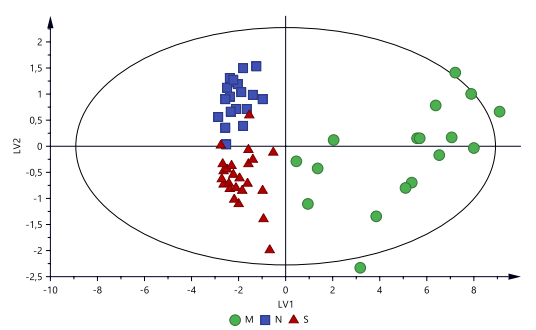

(g)

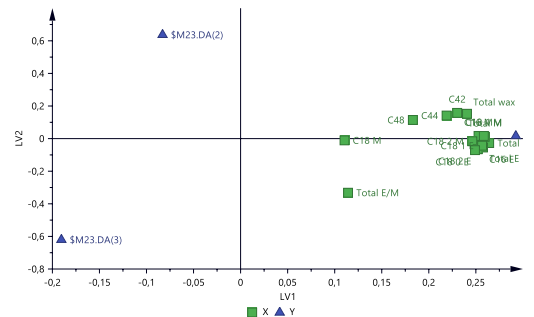

(h)

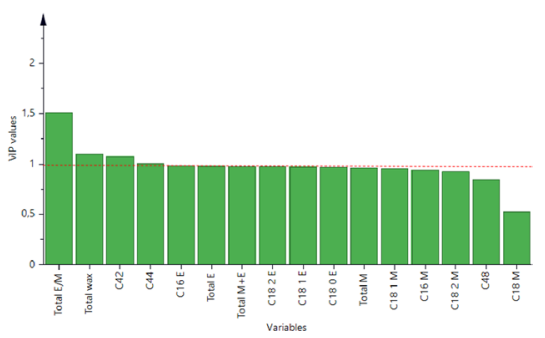

(i)

Fig. 3 OPLS-DA score $(\mathbf{a}, \mathbf{d}, \mathbf{g})$, loading $(\mathbf{b}, \mathbf{e}, \mathbf{h})$, and VIP $(\mathbf{c}, \mathbf{f}, \mathbf{i})$ plots of different olive oil varieties with respect to wax contents, fatty acid alkyl esters and combination of these parameters, respectively

orthogonal component explaining $34 \%$ of the total variance (Table 2). In calibration and validation sets only one and two $\mathrm{M}$ samples were misclassified as $\mathrm{S}$, respectively. All of the S samples were correctly grouped in calibration set and three samples were misclassified as $\mathrm{M}$ in the validation set while none of the $\mathrm{N}$ samples were correctly classified in both sets as can be seen from Table 2 . Totally, $67 \%$ of the calibration and $52 \%$ of the validation sets were correctly 
classified which was not enough for a robust differentiation model. Loading plot revealed that higher content of wax components was responsible in differentiation of $\mathrm{M}$ region samples (Fig. 3b). According to the VIP values, total wax, C42 and C44 were effective in differentiation (Fig. 3c).

Individual alkyl esters were also tested in terms of their discrimination ability on varietal level. When compared to wax esters alone (Fig. 3a), alkyl esters were found more successful in differentiation (Fig. 3d). OPLS-DA analysis revealed a clear classification model with two predictive and two orthogonal components; in detail, the first two significant LVs explained $58 \%$ of the total variance (Table 2). The average correct classification rate for $\mathrm{M}, \mathrm{N}$ and $\mathrm{S}$ region samples were found as $80 \%$ (out of 60 samples; five samples were misclassified as $\mathrm{S}$ and seven samples were misclassified as $\mathrm{N}$ ) and $65 \%$ (out of 31 samples; four samples were misclassified as $\mathrm{S}$ and seven samples were misclassified as $\mathrm{N}$ ) in calibration and validation sets, respectively whereas none of the samples was misclassified as M. According to score plot (Fig. 3d), M region samples were scattered into the right (positive) side of LV1, whereas the $\mathrm{S}$ and $\mathrm{N}$ samples were partially classified in the second and the third quartile with respect to positive and negative LV2, respectively. The OPLS-DA calibration model was successful in differentiation of $\mathrm{M}$ region samples from the rest while seven $\mathrm{S}$ and three $\mathrm{N}$ region samples overlapped with each other (Table 2). Loading plot (Fig. 3e) and VIP values (Fig. 3f) revealed E/M as the most influential parameter on discrimination.

As a last approach, OPLS-DA statistical model (Fig. 3g with LVs: $2+1, \mathrm{R}_{\text {cal }}^{2}: 0.67, \mathrm{R}_{\mathrm{cv}}^{2}: 0.62$ ) built with combination of FAAEs and wax data indicates that $\mathrm{M}, \mathrm{N}$ and $\mathrm{S}$ samples were correctly classified according to the genotype with some exceptions as explained in the misclassification table (Table 2). Model was built with 2 predictive and 1 orthogonal component and particularly the first two significant LVs explained $67 \%$ of the total variance. According to the score plot (Fig. 3g), M region samples were successfully separated in the right (positive) side of LV1 whereas N and S region samples were located on the opposite side. Moreover, these two regions ( $\mathrm{N}$ and $\mathrm{S}$ ) were separated from each other as located in the upper side (positive) of the first quarter and the lower side (negative) of the fourth quarter of LV2. Loading plot (Fig. $3 \mathrm{~h}$ ) showed that $\mathrm{M}$ region was placed apart from the rest in terms of the higher amounts of all the studied parameters. It can be concluded that $\mathrm{S}$ and $\mathrm{N}$ regions were more similar in terms of alkyl ester and wax profiles while $\mathrm{M}$ region was more apart than the rest (Table 1). $\mathrm{N}$ and $\mathrm{S}$ region olive oils contain similar amounts of FAAEs, and their FAAEs and wax ester contents are lower compared to $\mathrm{M}$ region olive oils. Considering only $\mathrm{N}$ and $\mathrm{S}$ regions, $S$ region samples had slightly higher amounts of individual alkyl esters. However, still there is an obvious separation between $\mathrm{N}$ and $\mathrm{S}$ region (Fig. $3 \mathrm{~g}$ ) oils although they have quite similar basic quality parameters (Table 1 ). Although FAAEs are quite related with the quality of the oil, a strong relation between these parameters and varietal factors are also well established with the recent study [10]. This differentiation between oils of these two regions can be related with the effect of olive variety since Ayvalik is the olive type in $\mathrm{N}$ part while Memecik is the dominant variety in $\mathrm{S}$ part.

In the present study, FAEE/FAME (total E/M), total wax as well as individual $\mathrm{C} 42$ and $\mathrm{C} 44, \mathrm{C} 16 \mathrm{E}$, total FAEEs and FAAEs (total of FAME + FAEE), having VIP values larger than 1 were found significant in discrimination of oils (Fig. 3i). Lastly, the classification model efficiency was determined with calibration and external validation data sets. As it could be seen from Table 2, OPLS-DA model revealed good discrimination ability with the average correct classification rate of $92 \%$ (out of 60 samples; 4 samples were misclassified as $\mathrm{S}$ and 1 sample was misclassified as $\mathrm{N}$ ) and $74 \%$ (out of 31 samples; 3 samples were misclassified as $\mathrm{S}$ and 5 samples were misclassified as $\mathrm{N}$ ) in calibration and validation data sets, respectively. Importance of wax esters and FAAEs in discrimination was obvious from the VIP plot (Fig. 3i). However, wax esters alone were not that effective in cultivar classification as explained previously. In the literature, wax esters of olives were also examined with some other parameters such as diacylglycerols, triacylglycerols, triterpenic acids and aldehydes to investigate their dependency on cultivar [19]. In the present study, it was found that effectiveness of alkyl esters on varietal differentiation could be improved when combined with wax contents. Since these compounds could be identified in the same sample chromatogram in a single run, their determination and application in fused form do not require any additional effort. As it has been shown in different studies, variety and growth region of olives used in oil extraction have significant effects on various compositional parameters of olive oil $[28,30]$. This study also indicates that variety has an influence on FAAE and wax content of olive oils. However, cultivation of olive cultivars outside of their traditional area can add further challenge for authentication studies.

\section{Conclusions}

In the present study, olive oil samples belonging to three varieties obtained from three distinct locations $(\mathrm{M}, \mathrm{N}$, and $\mathrm{S})$ were different in terms of their fatty acid profiles whereas two regions as $\mathrm{N}$ and $\mathrm{S}$ were similar and higher quality than $\mathrm{M}$ region samples. Wax esters alone were more successful in differentiation of these samples in terms of quality rather than variety since only $\mathrm{M}$ region samples having lower quality were separated from the rest. FAAEs, on the other hand, were found to be better in discrimination of three varieties compared to wax esters. 
Although FAAEs and wax profiles have been used only for quality purposes, olive variety has also an influence on these parameters as it is shown in this study. Studies which can be performed with more olive varieties could further help in the use of these parameters for authentication purposes. Furthermore, it was observed that FAAEs and wax contents in combination have a greater potential in olive oil authentication with respect to varietal origin compared to one-by-one forms of these compounds. Therefore, FAAEs and waxes together could be a promising alternative for authentication of olive oils. Their power in quality determination is still standing but their varietal effect is also valid in their usage as an authentication tool.

Acknowledgements We would like to thank the Environmental Research Center of Izmir Institute of Technology for their help in GC analysis and the Tariş Olive and Olive Oil Agriculture Sales Cooperatives Union for providing some of the olive oil samples.

Funding This study was supported by the Scientific and Technological Research Council of Turkey (TUBITAK) under the grant number TUBITAK-TOVAG 1150584.

\section{Declarations}

Conflict of interest The authors declare that they have no conflict of interest.

\section{References}

1. O. Uncu, B. Ozen, Trends Food Sci. Tech. 100, 164 (2020)

2. H. Jabeur, A. Zribi, R. Abdelhedi, M. Bouaziz, Food Chem. 169, $289(2015)$

3. [EU] Commission Regulation, Off. J. Eur. Union L23, 1 (2011)

4. R.B. Gómez-Coca, G.D. Fernandes, M. del Carmen PérezCamino, W. Moreda, LWT-Food Sci. Technol. 66, 378 (2016)

5. [IOC] International Olive Council, COI/T. 15/NC No 3/Rev. 5, 1 (2010)

6. L. Conte, C. Mariani, T. Gallina Toschi, S. Tagliabue, Riv. Ital. Sostanze Gr. 91, 21 (2014)

7. L. García-Vico, A. Belaj, L. León, R. de la Rosa, C. Sanz, A.G. Pérez, Food Control 91, 248 (2018)
8. M.D.C. Pérez-Camino, A. Cert, A. Romero-Segura, R. Cert-Trujillo, W. Moreda, J. Agr. Food Chem. 56, 6740 (2008)

9. G. Beltran, M.A. Bejaoui, A. Jimenez, A. Sanchez-Ortiz, J. Agr. Food Chem. 63, 5309 (2015)

10. A. Boudebouz, A. Romero, R. Boqué, L. Aceña, O. Busto, M. Mestres, J. Sci. Food Agr. 100, 3173 (2020)

11. G. Squeo, S. Grassi, V.M. Paradiso, C. Alamprese, F. Caponio, Food Control 102, 149 (2019)

12. R. Costa, G. Bartolomeo, E. Saija, R. Rando, A. Albergamo, G. Dugo, J. Food Quality 2017, 3078105 (2017)

13. [EU] Commission Delegated Regulation, Off. J. Eur. Union L326, 1 (2016)

14. [IOC] International Olive Council, COI/T.15/NC No. 3/Rev. 14, 1 (2019)

15. H. Jabeur, M. Drira, A. Rebai, M. Bouaziz, J. Agr. Food Chem. 65, 5375 (2017)

16. Á. Aragón, R.M. Toledano, J.M. Cortés, J. Villén, A. Vázquez, Food Chem. 129, 71 (2011)

17. A.M. Giuffrè, Eur. J. Lipid Sci. Tech. 115, 549 (2013)

18. A.M. Giuffrè, J. Am. Chem. Soc. 91, 1355 (2014)

19. S. Vichi, N. Cortés-Francisco, J. Caixach, G. Barrios, J. Mateu, A. Ninot, A. Romero, J. Agr. Food Chem. 64, 5985 (2016)

20. S.A. Wadood, G. Boli, Z. Xiaowen, I. Hussain, W. Yimin, Microchem. J. 152, 104295 (2020)

21. S. Amiry, M. Esmaiili, M. Alizadeh, Food Chem. 224, 390 (2017)

22. S. Pirsa, E. Banafshechin, S. Amiri, A. Rahimirad, J. Ghafarzadeh, J. Iranian Chem. Soc. 18, 1167 (2021)

23. I. Dogruer, H.H. Uyar, O. Uncu, B. Ozen, Food Chem. 345, 128815 (2021)

24. M. Biedermann, A. Bongartz, C. Mariani, K. Grob, Eur. Food Res. Technol. 228, 65 (2008)

25. [EEC] Commission Regulation, Off. J. Eur. Commun. L248, 1 (1991)

26. [IOC] International Olive Council, COI/T.20/Doc. No 28/Rev. 1, $1(2010)$

27. O. Uncu, B. Ozen, F. Tokatli, J. Sci. Food Agr. 100, 2153 (2020)

28. G. Gurdeniz, B. Ozen, F. Tokatli, Eur. Food Res. Technol. 227, $1275(2008)$

29. M. D'Imperio, G. Dugo, M. Alfa, L. Mannina, A.L. Segre, Food Chem. 102, 956 (2007)

30. O. Uncu, B. Ozen, Anal. Methods 8, 4872 (2016)

Publisher's Note Springer Nature remains neutral with regard to jurisdictional claims in published maps and institutional affiliations. 